\title{
Altered intestinal microflora and barrier injury in severe acute pancreatitis can be changed by zinc
}

\author{
Shi-yue Su${ }^{1}$, Qin-qing Tang ${ }^{\circledR}$ \\ 1. Department of Obstetrics and Gynecology, the First Affiliated Hospital of Anhui Medical University, No.218 Jixi Road, Hefei 230022, Anhui, China. \\ 2. Department of General Surgery, the First Affiliated Hospital of Anhui Medical University, No.218 Jixi Road, Hefei 230022, Anhui, China. \\ $\triangle$ Corresponding author: Qin-qing Tang, Email: tangqinqing@ahmu.edu.cn
}

(C) The author(s). This is an open access article distributed under the terms of the Creative Commons Attribution License (https://creativecommons.org/licenses/by/4.0/). See http://ivyspring.com/terms for full terms and conditions.

Received: 2020.03.13; Accepted: 2021.06.04; Published: 2021.06.16

\begin{abstract}
To investigate the effect of zinc $(\mathrm{Zn})$ supplementation on intestinal microflora changes and bacterial translocation in rats with severe acute pancreatitis (SAP), the rats were divided into the sham surgery (SS), SAP, $\mathrm{SS}+\mathrm{Zn}$, and SAP $+\mathrm{Zn}$ groups. Saline $(0.1 \mathrm{~mL} / 100 \mathrm{~g})$ and $5 \%$ sodium taurocholate were injected into the pancreaticobiliary duct of the rats in the SS and SAP + Zn groups, respectively. Intraperitoneal injection of 5 $\mathrm{mg} / \mathrm{kg} \mathrm{Zn}$ was performed immediately after injecting saline or $5 \%$ sodium taurocholate into the rats in both groups. Serum amylase and $\mathrm{Zn}$ levels, plasma endogenous endotoxin, intestinal permeability, and the positive rate of intestinal bacterial translocation were detected, haematoxylin and eosin (H\&E) staining was performed, and the pancreatic tissue scores were calculated for each group. In addition, immunohistochemical (IHC) staining was performed to evaluate the expression of IL-1 $\beta$ and TNF- $\alpha$. Real-time fluorescence quantitative PCR was used to quantify the gene copy numbers of Escherichia, Bifidobacterium, and Lactobacillus in the cecum. The levels of amylase and plasma endotoxin in the SAP group were significantly higher than those in the SS and SS + Zn groups. Intestinal mucosal permeability and intestinal bacterial translocation in the liver, pancreas, and mesenteric lymph nodes were increased in the SAP group. However, the levels of amylase and plasma endotoxin were decreased as a result of zinc supplementation in the SAP group. The expression of IL-1 $\beta$ and TNF- $\alpha$ was also reduced to a greater degree in the SAP + Zn group than in the SAP group. Moreover, alleviated intestinal mucosal permeability and intestinal bacterial translocation in the liver, pancreas, and mesenteric lymph nodes were found in the SAP $+\mathrm{Zn}$ group. The results of real-time quantitative PCR showed that the gene copy number of Escherichia increased with time, and the gene copy numbers of Lactobacillus and Bifidobacterium decreased over time. Zn supplementation prevented the release of TNF- $\alpha$ and IL-1 $\beta$, alleviated intestinal permeability and endotoxemia, reduced bacterial translocation, and inhibited changes in pathogenic intestinal flora in rats with SAP.
\end{abstract}

Key words: Endotoxin; IL-1 $\beta$; intestinal microflora; pancreatitis; TNF-a; zinc

\section{Introduction}

Approximately $80 \%$ of patients with acute pancreatitis (AP) have a good prognosis, with only minor symptoms. However, $20 \%$ of patients have a high mortality risk due to organ failure, with local and even systemic complications, which can lead to a high mortality rate of up to $50 \%[1,2]$.

The intestinal mucosal barrier plays an important role in maintaining intestinal function and preventing bacterial and toxin transfer into the blood circulation in the enteric cavity. An intact gut mucosa serves as an effective barrier between the luminal bacterial microbiome, stool contents, and systemic circulation [3].
Intestinal bacteria are the main source of sepsis infections when the abdominal organs become inflamed. Bacteria may enter the body through the damaged mucosa and cause bacterial translocation [4]. Severe acute pancreatitis (SAP) infection is considered to be the result of bacterial translocation (BT) from the gastrointestinal tract, and increased intestinal permeability has been implicated in this mechanism [5]. BT is defined as endogenous bacteria (or its products) colonising the intestinal tract through the intestinal mucosal barrier and reaching the mesenteric lymph nodes and other distant sites [6]. 
Intestinal barrier function, which controls uptake across the mucosa and prevents damage by harmful substances from lumens, mainly consists of intestinal microflora, a mucus layer, the epithelium, intestinal circulation, mucosal immune system, and gut motility [7]. A previous study demonstrated an increase in Gram-positive cocci, Gram-negative bacilli, and anaerobic microorganisms in the duodenum of animals with acute necrotising pancreatitis compared to the control group [8].

Zinc (Zn) is a trace element involved in signal transmission and immune response [9]. $\mathrm{Zn}$ has antioxidant and anti-inflammatory properties, and maintains redox balance by regulating $\mathrm{Zn}$-dependent enzymes, such as superoxide dismutase and matrix metalloproteinase [10, 11]. Previous studies have shown that the levels of $\mathrm{Zn}$ in the SAP group were lower than those in the control group, and that $\mathrm{Zn}$ supplementation was beneficial to the balance of the free radical content, the antioxidant enzyme system of rats with SAP, and the liver and kidney $[12,13]$.

However, the kinetics of functional impairment of the intestinal barrier in relation to pancreatic disease are unclear, and changes in the intestinal microflora have not been well elucidated. Therefore, we sought to investigate the SAP-associated bacterial translocation and intestinal flora changes, as well as IL-1 $\beta$, TNF- $\alpha$, and endotoxin levels in rats with SAP to determine the kinetics of intestinal barrier function impairment in Na-taurocholate-induced SAP models.
Moreover, the possible role of $\mathrm{Zn}$ supplementation in modulation of IL-1 $\beta$ and TNF- $\alpha$, bacterial translocation, and changes in pathogenic intestinal flora in the treatment of SAP were also explored (Fig. $1)$.

\section{Materials and Methods}

\section{Materials}

Sodium taurocholate was purchased from Sigma (USA). The Toxin Sensor ${ }^{\mathrm{TM}}$ Endotoxin Kit was supplied by Kingsley Biotechnology Company (Nanjing, China). The Soil Genome DNA Rapid Extraction Kit and qPCR kit were obtained from Sangon Bio Company (Shanghai, China). Zn sulphate was obtained from the Tianjin Bodi Bio Company of China.

\section{Experimental animals}

The experiments were conducted according to the guidelines of the committee of the Anhui Medical University of China. Seventy-two SD male rats weighing 200-300 g, provided by the Laboratory Animal Center of Anhui Medical University, were randomly divided into a sham surgery (SS) group ( $\mathrm{n}=$ $18)$, SS + Zn group $(\mathrm{n}=18)$, SAP group $(\mathrm{n}=18)$, and $\mathrm{SAP}+\mathrm{Zn}$ group $(\mathrm{n}=18)$. Each group was further divided into $6 \mathrm{~h}(\mathrm{n}=6), 12 \mathrm{~h}(\mathrm{n}=6)$, and $24 \mathrm{~h}$ subgroups $(\mathrm{n}=6)$. The rats were fasted overnight, except for free access to water before surgery.

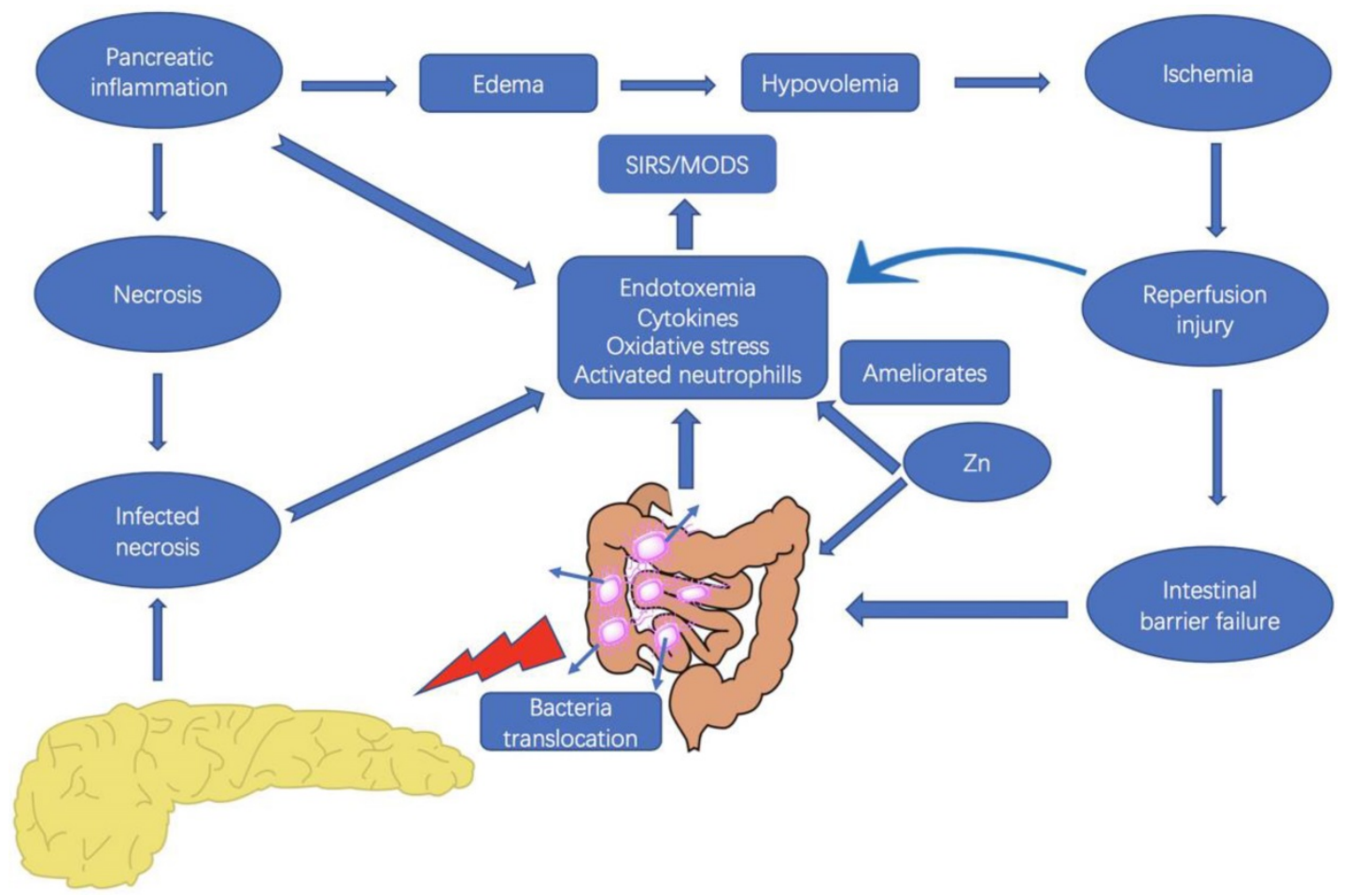

Figure 1. Interaction between the pancreas and the intestine, and the possible effects of zinc in severe acute pancreatitis. Zinc supplementation plays a role in the inhibition the release of inflammatory cytokines, as well as the reduction of bacterial translocation and endotoxemia. 
All of the rats were anesthetized with $10 \%$ chloral hydrate $(0.3 \mathrm{~mL} / 100 \mathrm{~g})$ by intraperitoneal injection. A $1.5 \mathrm{~cm}$ incision was made in the mid-abdomen under aseptic conditions, and 5\% sodium taurocholate reagent $(0.1 \mathrm{~mL} / 100 \mathrm{~g})$ was injected into the pancreaticobiliary duct. Saline $(0.1$ $\mathrm{mL} / 100 \mathrm{~g}$ ) was injected into the pancreaticobiliary duct in the SS group. Both retrograde injections were administered into the pancreatic duct within $30 \mathrm{~min}$ using an automatic infusion pump. For the SAP $+\mathrm{Zn}$ group, $5 \mathrm{mg} / \mathrm{kg} \mathrm{Zn}$ sulphate was administered by immediate intraperitoneal injection after a single injection of 5\% sodium taurocholate. For the SS + Zn group, intraperitoneal injection of $5 \mathrm{mg} / \mathrm{kg} \mathrm{Zn}$ sulphate was administered immediately after saline injection into the pancreaticobiliary duct.

Following closure of the abdomen, the rats were re-operated after 6,12 , and $24 \mathrm{~h}$. Next, blood samples, mesenteric lymph nodes, liver, pancreas, ileum tissues, and cecum faeces were collected for further analysis.

\section{Determination of serum amylase, TNF- $\alpha$, IL-1 $\boldsymbol{\beta}$, endotoxin, and serum $\mathbf{Z n}$}

Serum amylase levels were analysed using an automatic HITACHI-7150 analyser (Japan). Briefly, 1 $\mathrm{ml}$ of inferior vena cava blood was placed into an anticoagulant tube and centrifuged for $15 \mathrm{~min}$ at 4000 rpm to separate the plasma. The endotoxin content in the plasma was determined using the endotoxin Limulus reagent from Nanjing Jiancheng BioCompany, China. The rats were treated in the same way in both the SAP + Zn and SAP groups after the administration of $\mathrm{Zn}$ sulphate 2 weeks later. One millilitre of inferior vena cava blood was collected with a syringe, and the serum was obtained by centrifugation $\left(4^{\circ} \mathrm{C}, 15 \mathrm{~min}\right.$ at $\left.4000 \mathrm{rpm}\right)$. Each blood sample was placed in an EDTA anticoagulation container to prevent clotting. The samples were then placed in a centrifuge to separate the serum at 3500 rpm for $5 \mathrm{~min}$. The serum samples were stored at a temperature of $-80^{\circ} \mathrm{C}$ until required for analysis. The serum $\mathrm{Zn}$ concentration was then determined using an atomic absorption spectrophotometer (Z-8100, Hitachi, Japan). The serum concentrations of TNF- $\alpha$ and IL-1 $\beta$ were determined using ELISA (A\&D Company of the United States). The experiments were performed in strict accordance with the manufacturer's instructions.

\section{Intestinal permeability assay}

The small intestine $(6 \mathrm{~cm})$ was prepared and gently rinsed with saline. Subsequently, one end of the small intestine was closed, and the other end was ligated with a gavage needle. Then $0.2 \mathrm{ml}$ Evans blue was injected with a $1 \mathrm{ml}$ syringe into the intestinal tissue, and the processed intestinal tissue was placed in a $20-\mathrm{ml} \mathrm{Krebs}$ beaker in a $37^{\circ} \mathrm{C}$ water bath. The sac tissue was removed $30 \mathrm{~min}$ later, and the intestine was rinsed with saline until the rinse solution was clear. Next, the mixture was dried at $37^{\circ} \mathrm{C}$ for $24 \mathrm{~h}, 1 \mathrm{ml}$ formamide solution was added, and the mixture was incubated at $50^{\circ} \mathrm{C}$ for $24 \mathrm{~h}$. The solution was centrifuged, and the supernatant was analysed using an ultraviolet spectrophotometer at a wavelength of $620 \mathrm{~nm}$. The Evans blue content ( $\mu \mathrm{g} / \mathrm{g}$ ) was calculated according to the standard curve. The ultrastructure of the small intestinal mucosal epithelial cells was examined by transmission electron microscopy. Briefly, specimens of small intestinal mucosa were collected and placed on a precooled glass slide, and then $2.5 \%$ glutaraldehyde solution at $4{ }^{\circ} \mathrm{C}$ was dripped rapidly onto the slide. The specimens were then cut into $0.5-1 \mathrm{~mm}^{2}$ pieces and fixed in $2.5 \%$ glutaraldehyde solution at $4^{\circ} \mathrm{C}$ for $6 \mathrm{~h}$. The ultrastructure of the small intestinal mucosa was then observed by transmission electron microscopy after double distilled water washing and natural drying.

\section{Histological evaluation and immunohistochemical studies}

The sections of the pancreas and intestine were fixed with $4 \%$ paraformaldehyde and stained with haematoxylin and eosin (H\&E). Based on the Spormann scoring system, pancreatitis can be classified into enema, haemorrhage, leukocyte infiltration, parenchymal necrosis, and adipose tissue necrosis according to the degree of severity [14].

Frozen and paraffin-embedded sections of the pancreas $(5 \mu \mathrm{m})$ were subjected to standard avidin-biotin-peroxidase immunohistochemical methods. The sections were deparaffinized and rehydrated. The following antibodies were used: (1) rabbit anti-IL-1 $\beta$ polyclonal antibodies (1:50; Santa Cruz Biotechnology, Santa Cruz, CA, USA); and (2) mouse anti-TNF-a monoclonal antibody (1:100; Santa Cruz Biotechnology, Santa Cruz, CA, USA). The positive cells were determined by the presence of light brown granules in the cytoplasm. The distribution of positive cells was detected in non-overlapping fields in each section. The expression of IL- $1 \beta$ and TNF- $\alpha$ proteins was semi quantitatively analysed in 15 visual fields by calculating the average optical density (OD) of positive cells. Image-Pro Plus software (version 6.0) was used to perform semi-quantitative analysis on the expression of IL-1 $\beta$ and TNF- $\alpha$, and to calculate the positive optical densities of IL-1 $\beta$ and TNF- $\alpha$.

\section{Intestinal bacterial translocation assay}

Under aseptic conditions, the lymph nodes, liver, 
and pancreatic tissues were ground sufficiently and placed in a $37^{\circ} \mathrm{C}$ incubator for nutrient requirement and anaerobic culture for 2 days before calculating the intestinal bacterial translocation rate.

\section{Extraction of DNA from cecum bacteria}

Faecal samples $(0.1 \mathrm{~g})$ were mixed with $10 \mathrm{ml}$ phosphate buffer for $5 \mathrm{~min}$ and then centrifuged for $10 \mathrm{~min}$ at $1000 \mathrm{rpm}$. Next, the bacterial genomic DNA was extracted from the supernatant and preserved at $-20^{\circ} \mathrm{C}$.

\section{Polymerase chain reaction (PCR)}

Genomic DNA extracted from Escherichia, Lactobacillus, Bifidobacterium, and 16S rDNA was used for PCR amplification. The reaction system (Shanghai Sangon Biotech, Co., Ltd, China) consisted of $10 \times$ PCR buffer $2.5 \mu \mathrm{l}, 10 \mathrm{mmol} / \mathrm{L}$ dNTP mixture $0.5 \mu \mathrm{l}, 10$ $\mu \mathrm{M}$ upstream primers, $10 \mu \mathrm{M}$ downstream primers, and $0.2 \mu \mathrm{l}$ of Ex Taq DNA polymerase. Deionised water was added to the mixture to a final volume of $25 \mu$. The PCR amplification procedure was performed at $94^{\circ} \mathrm{C}$ for $5 \mathrm{~min} 30 \mathrm{~s}$, annealing at $57^{\circ} \mathrm{C}$ for $30 \mathrm{~s}$, and extension at $72^{\circ} \mathrm{C}$ for $8 \mathrm{~min}$ for a total of 35 cycles. Following amplification, $10 \mu \mathrm{l}$ of the PCR product was taken, and $2 \%$ agarose gel electrophoresis was performed simultaneously with the DNA Marker.

\section{Construction of a standard plasmid}

The amplified PCR products were purified and linked to the pMD18 simple-T vector. Escherichia Top10 was transformed, and four white clones were randomly selected. Next, the positive clones were screened according to blue-white selection and verified via PCR. A small amount of plasmid DNA was then prepared and identified by PCR and sent to Sangon BioCompany for sequencing. After accurate quantification using an ultraviolet spectrophotometer, the number of copies was calculated according to the following formula, diluted ten times, and then stored as a standard at $-20^{\circ} \mathrm{C}$.

Copy number $($ copies $/ \mu \mathrm{l})=$ Concentration $(\mathrm{ng} / \mu \mathrm{l}) \times$ $6.02 \times 10^{14} /$ molecular weight

\section{Quantitative analysis of Escherichia, Lactobacillus, and Bifidobacterium by real-time quantitative PCR}

The standard curve was established using real-time fluorescence quantitative PCR using a 10-fold gradient diluted plasmid standard as a template. The PCR reaction was performed in a $10 \mu \mathrm{l}$ system, containing $5 \mu \mathrm{l}$ Real Master Mix (SYBR Green), $1 \mu$ template, $10 \mu \mathrm{M}$ upstream primers, $10 \mu \mathrm{M}$ downstream primers, and 3.6 $\mu$ l deionised water. PCR amplification was performed at $95^{\circ} \mathrm{C}$ for $3 \mathrm{~min}$, followed by $94^{\circ} \mathrm{C}$ for $15 \mathrm{~s}$, annealing at $57^{\circ} \mathrm{C}$ for $20 \mathrm{~s}$, and extension at $72^{\circ} \mathrm{C}$ for $30 \mathrm{~s}$ for 45 cycles. A standard curve was obtained. Genomic DNA samples of Escherichia, Lactobacillus, and Bifidobacterium were tested. The number of DNA copies in the samples was determined according to the measured $\mathrm{Ct}$ value and standard curve. The following primers were used: Escherichia: F: 5'-GTTAATACCTTTGCTCATTGA-3', R: 5'-ACCAGGGTATCTTAATCCTGTT-3'; Lactobacillus: F: 5'-AGCAGTAGGGAATCTTCCA-3' R: 5'-CACCGCTACACATGGAG-3', Bifidobacterium: F: 5'-TCGCGTC(C/T)GGTGTGAAAG-3' R: 5'-CCACAT CCAGC(A/G)TCCAC-3', 16S: F: 5'-ACGGGGGGC CTACGGGAGGCAGCAG-3'， R: 5'-ATTACCGCG GCTGCTGG-3'.

\section{Statistical analysis}

Data were processed using SPSS software (version 17.0). The normality of the distribution was tested using the Kolmogorov-Smirnov test. Normally distributed data are expressed as the mean \pm standard deviation (SD). Repetitive measure analysis of variance was used to analyse the influence of processing and time on each group, as well as the interaction between processing and time. The LSD- $t$ method was used to compare the two treatments. P-values < 0.05 were considered statistically significant, and p-values $<0.01$ were considered dramatic statistically significant.

\section{Results}

\section{Lowering of the amylase levels caused by $\mathrm{Zn}$ supplementation in rats with SAP}

Acute pancreatitis was diagnosed by elevation of the serum alpha-amylase level. The levels of amylase in the SAP group were higher than those in the SS and SS + Zn groups. Statistical analysis showed that there was a significant difference between the SAP and SS groups. However, Zn supplementation decreased amylase levels. In the subgroup analysis, the difference between the SAP and SAP $+\mathrm{Zn}$ groups was significant after $12 \mathrm{~h}$ and $24 \mathrm{~h}$ (Fig. 2a).

\section{Reduction in plasma endotoxin caused by $\mathbf{Z n}$ supplementation in rats with SAP}

Plasma endotoxin levels in the SAP group were higher than those in the SS and SS + Zn groups. Statistical analysis showed that there was a significant difference between the SAP, SS, and SS + Zn groups. However, the difference between the SAP and SAP + $\mathrm{Zn}$ groups was only significant in the $24 \mathrm{~h}$ subgroup (Fig. 2b). 

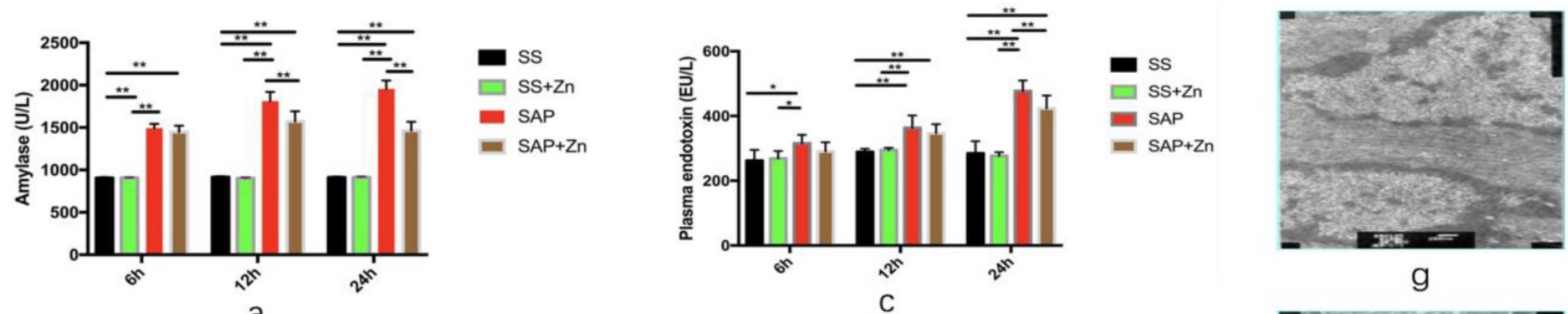

a
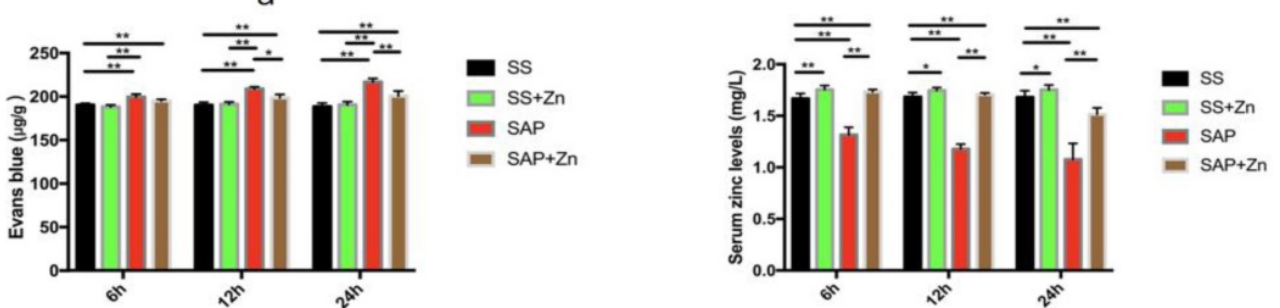

$\mathrm{b}$

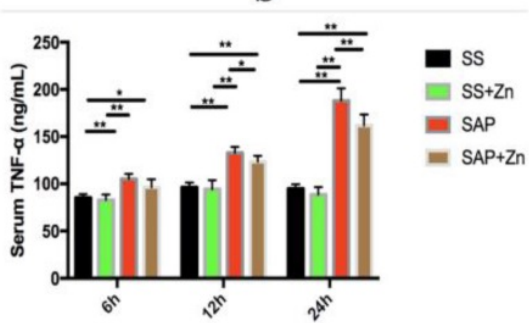

d
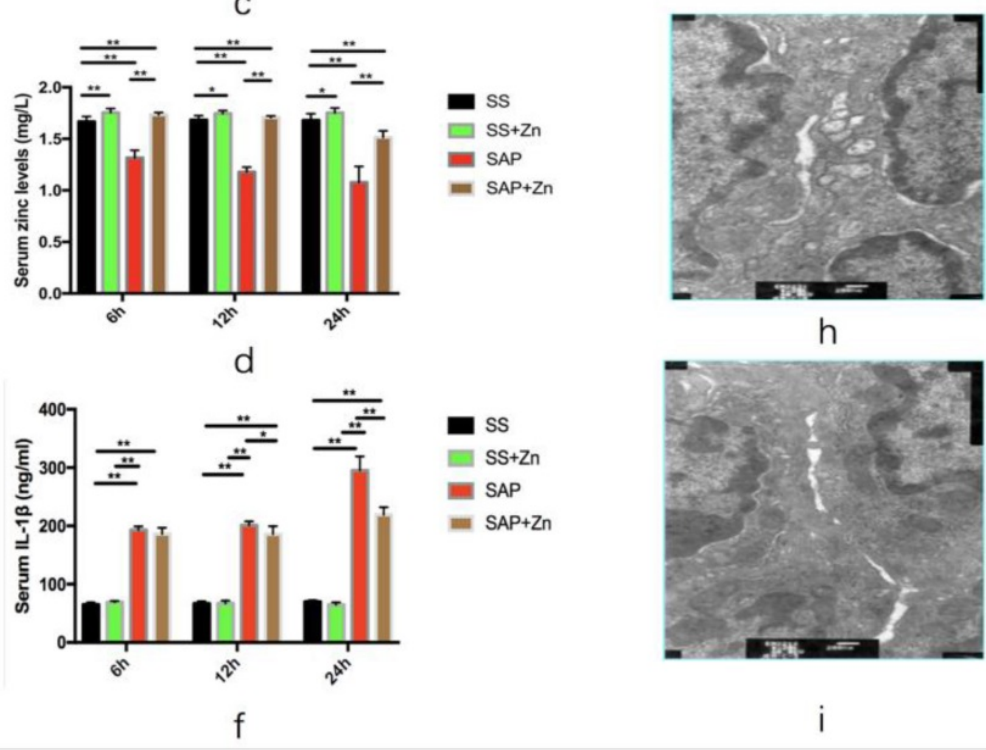

$\mathrm{h}$

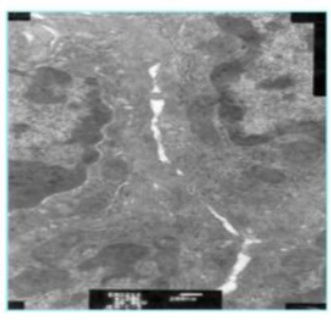

e

Figure 2. Levels of serum amylase, plasma endotoxin, and Evans blue were significantly increased, and those levels were markedly decreased in the SAP $+\mathrm{Zn}$ group compared to those in the SAP group. Levels of serum amylase in SAP $+\mathrm{Zn}$ group were significantly decreased compared to those in the $12 \mathrm{~h}$ and $24 \mathrm{~h}$ SAP group (a). Levels of plasma endotoxin in the SAP + Zn group were significantly decreased compared to those in the $24 \mathrm{~h}$ SAP group (b). Levels of Evans blue content in SAP + Zn group were significantly decreased compared to those in the $12 \mathrm{~h}$ and $24 \mathrm{~h}$ SAP groups (c). Levels of serum Zn levels in the SAP group were significantly decreased compared to those in the SS group and in the $6 \mathrm{~h}, 12 \mathrm{~h}$, and $24 \mathrm{~h}$ SAP groups. However, the levels in the SAP + Zn group were increased compared to those in the SAP group (d). Levels of serum TNF- $\alpha$ and IL- $1 \beta$ in the SAP group were significantly increased compared to those in the SS group and SS + Zn group, and in the $6 \mathrm{~h}, 12 \mathrm{~h}$, and $24 \mathrm{~h}$ SAP groups. However, the levels in the SAP $+\mathrm{Zn}$ group decreased significantly compared to those in the SAP group (e, f). The intercellular space was found to be widened in the SAP group (h) compared to the SS group (g), as observed by transmission electron microscopy. However, the injury was less severe in the SAP $+\mathrm{Zn}$ group (i) than in the SAP group. The data are expressed as means \pm $\mathrm{SD}, *_{\mathrm{p}}<0.05$ and $* * \mathrm{p}<0.01$.

\section{Reduction of intestinal permeability caused by Zn supplementation in rats with SAP}

The SAP group showed higher dye extravasation than the SS and SS + Zn groups on the basis of Evans blue exudation, showing that intestinal mucosal permeability was increased in the SAP group. The Evans blue content was significantly decreased in the $\mathrm{SAP}+\mathrm{Zn}$ group $12 \mathrm{~h}$ and $24 \mathrm{~h}$ later than that in the $\mathrm{SAP}$ and $\mathrm{SS}+\mathrm{Zn}$ groups (Fig. 2c).

Increase in serum Zn levels in the SAP + Zn group caused by $Z n$ supplementation when compared to rats with SAP

The serum Zn levels in the SAP group decreased significantly compared to the SS and SS + Zn groups, but increased in the SAP + Zn group compared to the SAP group (Fig. 2d).

\section{Reduction of serum TNF- $\alpha$ and IL- $1 \beta$ levels caused by $\mathrm{Zn}$ supplementation in rats with SAP}

The TNF- $\alpha$ and IL-1 $\beta$ serum levels in the SAP group were higher than those in the SS and SS + Zn groups. However, the levels of TNF- $\alpha$ and IL-1 $\beta$ were significantly decreased in the SAP $+Z n$ group $12 \mathrm{~h}$ and $24 \mathrm{~h}$ later than those in the SAP group (Fig. 2e and Fig. 2f).

\section{Inhibition of IL-1 $\beta$ and TNF- $\alpha$ release and alleviation of SAP severity by $\mathrm{Zn}$ supplementation according to histopathological examination and immunohistochemical staining}

Oedema, haemorrhage, and leukocyte infiltration were observed in the SAP group. The pancreatic tissue scores, as well as the positive optical densities (ODs) of IL-1 $\beta$ and TNF- $\alpha$ increased significantly over time. However, these scores and OD values were significantly decreased in the SAP $+\mathrm{Zn}$ group $12 \mathrm{~h}$ and $24 \mathrm{~h}$ later than those in the SAP group. HE staining of the intestinal tissue showed neutrophil infiltration into the intestinal tissue in the SAP group (Fig. 3). 

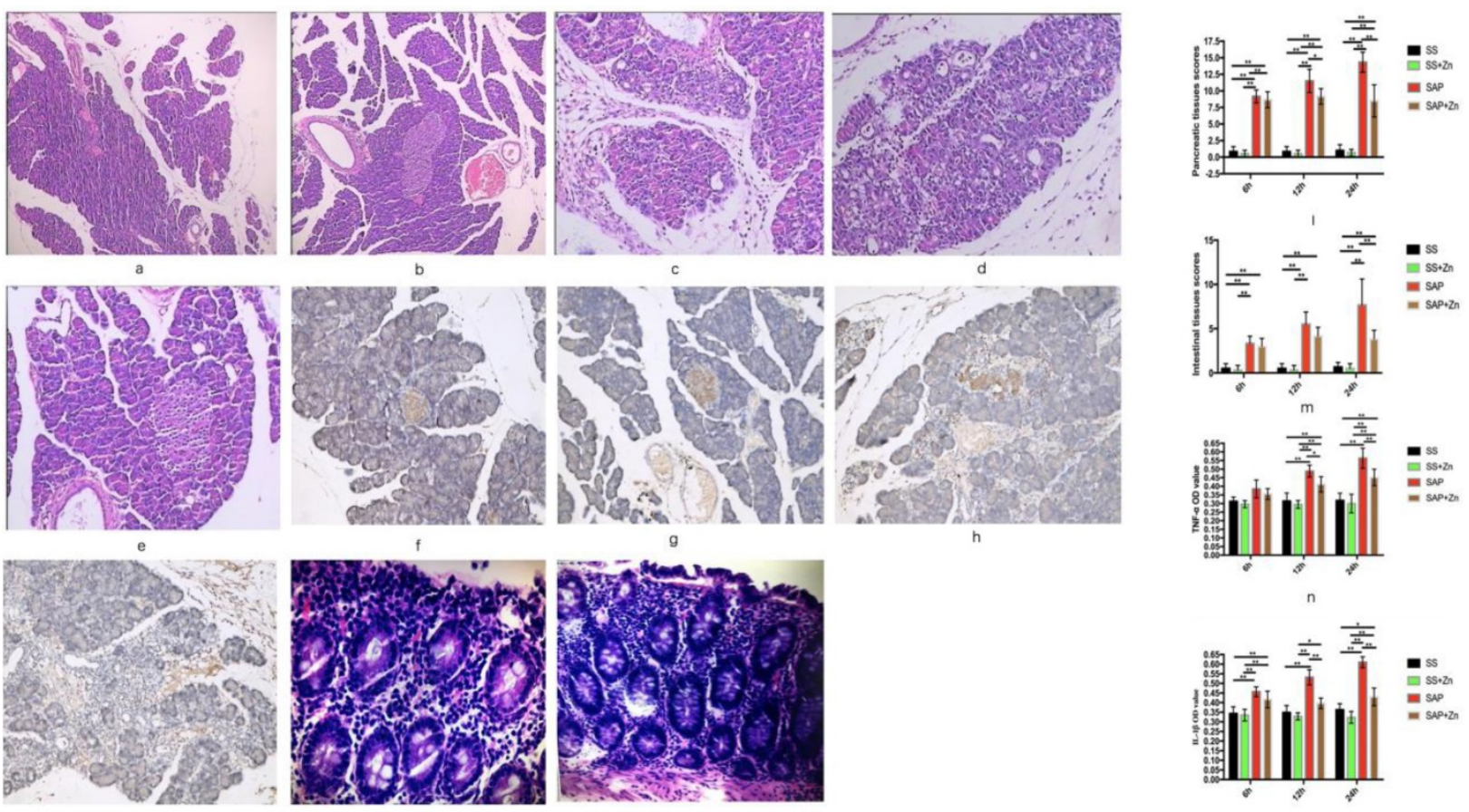

Figure 3. HE staining of the pancreatic tissue of the SS group $(\mathrm{HE} \times 100)$, showing normal pancreatic tissue $(\mathbf{a}, \mathbf{b})$. HE staining of the SAP $24 \mathrm{~h}$ group, showing interstitial oedema and neutrophil infiltration into the pancreatic tissue $(\mathrm{HE} \times 400)(\mathrm{c}, \mathrm{d})$; and showing alleviated oedema and neutrophils infiltration in the Zn-treated SAP group (24 h) (HE $\times 400)$ (e). Immunohistochemical analysis of IL-1 $\beta$ expression in the SS group $(\times 400)(f)$; immunohistochemical analysis of TNF- $\alpha$ expression in the SS group $(\times 100)(\mathrm{g})$; immunohistochemical analysis of IL-1 $\beta$ expression in the SAP $24 \mathrm{~h}$ group $(\times 400)(\mathrm{h})$; immunohistochemical analysis of TNF- $\alpha$ expression in the SAP $24 \mathrm{~h}$ group $(\times 400)(\mathbf{i})$. HE staining of the intestinal tissue showed neutrophil infiltration into the intestinal tissue (HE $\times 400)(j, k)$. Pancreatic tissues scores of the SAP $6 \mathrm{~h}$, $12 \mathrm{~h}$, and $24 \mathrm{~h}$ groups; the scores increased with time. However, the pancreatic tissue scores decreased in the $\mathrm{Zn}$-treated SAP group (I). Intestinal tissues scores of the SAP $6 \mathrm{~h}$, $12 \mathrm{~h}$, and $24 \mathrm{~h}$ groups; the scores increased with time. However, the intestinal tissue scores decreased in the Zn-treated SAP group (m). TNF- $\alpha$ OD value of the SAP $6 \mathrm{~h}, 12 \mathrm{~h}$, and $24 \mathrm{~h}$ group; the OD values increased with time. The OD value was significantly decreased in the $12 \mathrm{~h}$ and $24 \mathrm{~h} \mathrm{Zn}$-treated SAP groups (n). IL-1 3 OD value of the SAP $6 \mathrm{~h}$, $12 \mathrm{~h}$, and $24 \mathrm{~h}$ groups; the OD

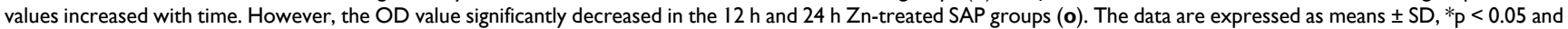
$* *_{p}<0.01$

\section{Zn leads to a significant reduction in translocated bacteria in the liver, pancreas, and mesenteric lymph nodes in comparison to the SAP group}

The amount of translocated bacteria in the liver was much larger in the SAP group than in the SS and $\mathrm{SS}+\mathrm{Zn}$ groups. However, the amount of translocated bacteria was significantly decreased in the SAP $+\mathrm{Zn}$ group after $12 \mathrm{~h}$ and $24 \mathrm{~h}$ compared to the SAP group (Fig. 4a). The amount of translocated bacteria in the pancreas and mesenteric lymph nodes was significantly higher in the SAP group $12 \mathrm{~h}$ and $24 \mathrm{~h}$ later than that in the SS group. Zn significantly decreased the amount of translocated bacteria compared to the SAP group (Figs. $4 \mathrm{~b}-\mathrm{c}$ ).

\section{Reduction in gene copy number of Escherichia, and increase in Bifidobacterium and Lactobacillus in the SAP + Zn group compared to the SAP group}

Samples isolated from the cecum were analysed. The dissolution curves of the three species of bacteria and internal reference were generated, with temperature as the abscissa. The dissolution curves showed a single peak, which demonstrated the specificity of the primers. The absolute quantification of the three species of bacteria showed that the gene copy number of $E$. coli in the SAP group was significantly higher than that in the SS and SS + Zn groups, while the gene copy numbers of Bifidobacterium and Lactobacillus were significantly lower than those in the SS and SS + Zn groups. Additionally, the gene copy number of Escherichia increased with time, while those of Lactobacillus and Bifidobacterium decreased. However, the gene copy number of Escherichia decreased, and Bifidobacterium and Lactobacillus increased in the SAP $+\mathrm{Zn}$ group compared to those in the SAP group (Fig. 5 and Fig. S1). The data are expressed as the mean $\pm S D,{ }^{*} p<0.05$ and ${ }^{* *} \mathrm{p}<0.01$.

\section{Discussion}

Bacterial translocation is defined as the translocation of intestinal bacteria from the intestinal cavity to the mesentery or other extraintestinal organs, including mesenteric lymph nodes (MLNs) and distant organs [15]. Many studies have confirmed the presence of bacterial translocation in critically ill patients and their relationship with the development 
of sepsis [16-19]. According to previous studies, bacterial translocation is widely accepted as the main source of systemic infection and may play an important role in the pathogenesis of sepsis in critically ill patients [20, 21]. Multiple organisms are

Liver

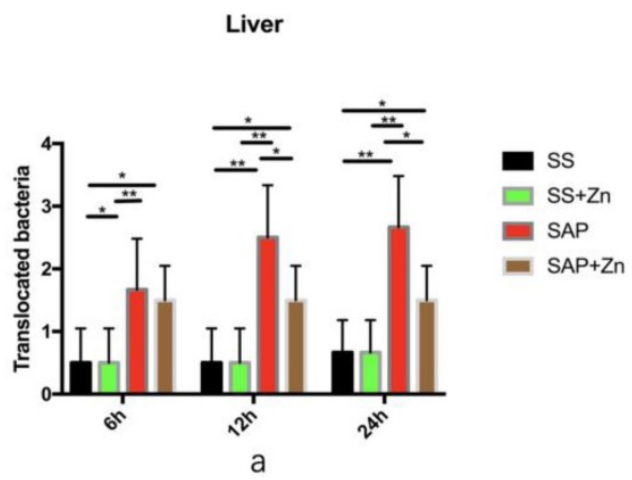

Mesenteric lymph nodes

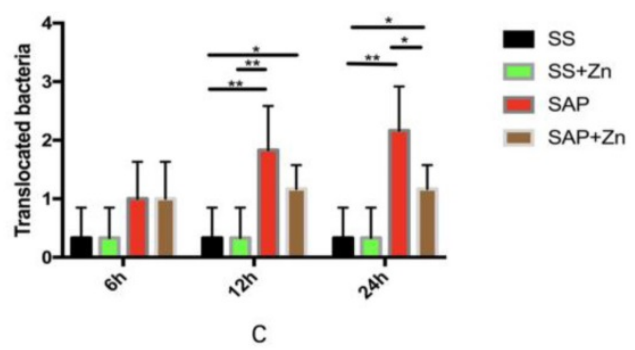

commonly observed in the blood specimens of patients with SAP using denaturing gradient gel electrophoresis [22]. However, the changes in the intestinal microflora in SAP remain unclear.

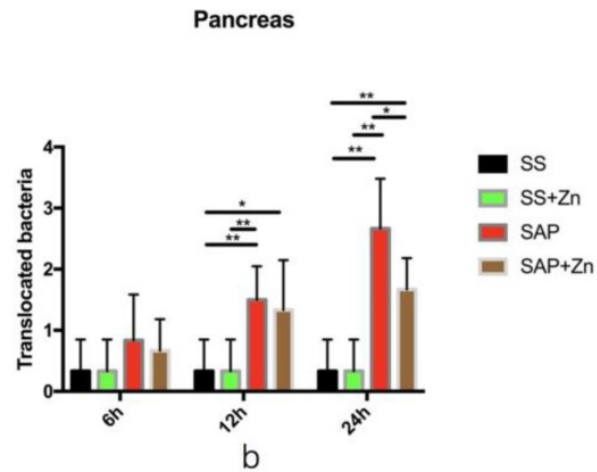

Figure 4. Translocated bacteria in the liver, pancreatic tissues, and mesenteric lymph nodes. Liver (a); pancreas (b); mesenteric lymph nodes (c). The data are expressed as means $\pm S D, * p<0.05$ and $* * p<0.01$.

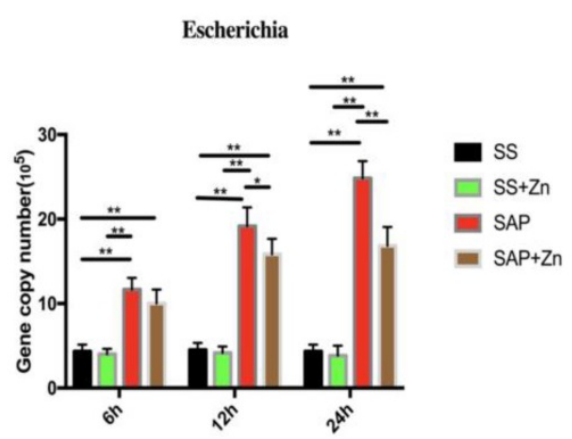

a

Bifidobacterium

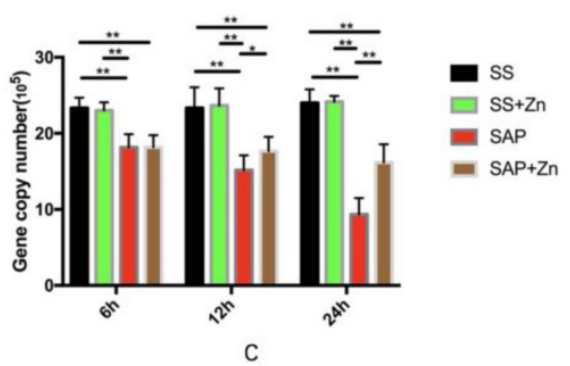

Lactobacillus

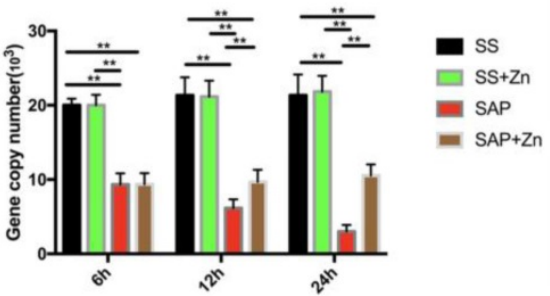

b

Figure 5. The gene copy number of Escherichia in the SS, SAP, and SAP + Zn groups (a). The gene copy number of Lactobacillus in the SS, SAP, and SAP + Zn groups (b). The gene copy number of Bifidobacterium in the SS, SAP and SAP $+\mathrm{Zn}$ groups (c). 
Changes in the intestinal flora are related to the pathogenesis of several inflammatory disorders [23]. However, evidence for the role of intestinal flora changes in SAP remains insufficient due to the limited number of studies discussing changes in intestinal microbiota in patients with SAP. E. coli is the most common bacteria associated with AP infections [24]. $\mathrm{Wu}$ et al. showed that the amount of Bifidobacteria and Lactobacillus decreased, while the amount of E. coli increased in patients with acute pancreatitis accompanied by concurrent infection. Bifidobacteria play a role in the prevention of pancreatic infections [25]. Tan et al. found that the amount of Bifidobacterium and Lactobacillus decreased in patients with SAP compared to that observed in patients with mild acute pancreatitis [26].

In this study, significant changes in microbial composition in the cecum were observed between the SAP group and the SS and SS + Zn groups. In the SAP group, Escherichia increased significantly, whereas Bifidobacterium and Lactobacillus decreased significantly. Thus, our research is in accordance with previous studies. Bifidobacterium and Lactobacillus have many beneficial effects on the stabilisation of intestinal barriers. The reduction of these beneficial bacteria and the increase of potentially pathogenic bacteria, such as Escherichia, correlates with intestinal flora disorder and SAP progression.

The main function of $\mathrm{Zn}$ is to act as a cofactor for the enzyme or structural element of the protein. Zn deficiency can result in ineffective control of pathogens and intestinal barrier dysfunction [27, 28, 29]. Some animal models have shown that $\mathrm{Zn}$ supplementation can reduce the severity of sepsis [30, 31]. Reed et al. demonstrated that microbes in the gut affect Zn levels [32]. The availability of $\mathrm{Zn}$ affects intestinal flora [33], and Zn deficiency is common in patients with CP [34]. However, studies concerning the $\mathrm{Zn}$ status in patients with acute pancreatitis are limited.

Through our research, $\mathrm{Zn}$ was found to alleviate intestinal permeability, bacterial translocation, endotoxemia, and the severity of SAP. The composition of the intestinal microbiota can also be altered by $\mathrm{Zn}$ in the progression of SAP. The expression of IL-1 $\beta$ and TNF- $\alpha$ was significantly decreased in the SAP $+Z n$ group. The above discussion indicates that $\mathrm{Zn}$ affects the composition of intestinal microbiota and inhibits the progression of SAP.

$\mathrm{Zn}$ homeostasis disorders in patients with pancreatitis are related to the progression of the inflammatory process [35]. Osman et al. demonstrated that $\mathrm{Zn}$ is useful in AP because it eliminates harmful enzymes from circulation by increasing the stimulation of 2-macroglobulin synthase and RES [36]. Low intracellular $\mathrm{Zn}$ levels have also been found to be associated with DNA damage, oxidative stress, antioxidant defence, and DNA repair, and reduced Zn is a potential marker for the treatment of resistant depression and the immune/inflammatory response in depression [37]. There is also evidence that $\mathrm{Zn}$ is an important antioxidant [38]. Oxidative stress is characterised by an imbalance between free radical exposure and antioxidant defence, which includes small molecular weight antioxidants, such as metallothionin and antioxidant enzymes. Zn supplementation alleviates oxidative stress, which may be a possible mechanism for maintaining gut barriers and reducing the release of cytokines and bacteria into the bloodstream in rats with SAP.

Zn plays an important role in intensifying the immunological response and has a protective effect on BT. Moreover, Zn deficiency is associated with increased systemic inflammation and increased nuclear factor-kB (NF-kB) activity [39, 40]. Zn supplementation has anti-inflammatory effects, reduces intestinal permeability, and increases villus height, Villin expression, and the amount of intestinal brush border enzyme [41, 42]. Hence, Zn supplementation alleviates inflammation, which may be another possible mechanism for maintaining gut barriers and reducing the severity of SAP.

\section{Conclusions}

The results of this study showed that intestinal bacteria translocated, and the composition of intestinal bacteria changed in the SAP group. Zn prevented the release of TNF- $\alpha$, IL- $1 \beta$, and bacteria into the bloodstream, reducing bacterial translocation, and inhibiting changes in the pathogenic intestinal flora, which may be important in the treatment of SAP. Maintaining the gastrointestinal microecological balance may be an effective way to regulate SAP progression, and supplementation with $\mathrm{Zn}$ is one possible mechanism.

\section{Supplementary Material}

Supplementary figure.

http://www.medsci.org/v18p3050s1.pdf

\section{Acknowledgements}

This work was supported by the University Natural Science Research Project of Anhui Province (KJ2020A0191) and the Training Program of the National Natural Science Foundation of the First Affiliated Hospital of Anhui Medical University of China (Grant No. 2013kj08). 


\section{Compliance with ethical standards}

The study was approved by the Ethical Committee of the Anhui Medical University of China. The experiments were performed in accordance with the committee guidelines.

\section{Competing Interests}

The authors have declared that no competing interest exists.

\section{References}

1. Pandol SJ, Saluja AK, Imrie CW, et al.Acute pancreatitis: Bench to the bedside. Gastroenterology. 2007; 132:1127-51.

2. Pezzilli R, Uomo G, Zerbi A, et al. Diagnosis and treatment of acute pancreatitis: the position statement of the Italian Association for the study of the pancreas. Dig Liver Dis. 2007; 40: 803-8.

3. Pinzone MR, Celesia BM, Di Rosa M, et al. Microbial translocation in chronic liver diseases. Int J Microbiol. 2012; 2012: 694629.

4. Li Q, Zhang $Q$, Wang $C$, et al. Disruption of tight junctions during polymicrobial sepsis in vivo. J Pathol. 2009; 218:210-21.

5. Jha RK, Yong MQ, Chen SH. The protective effect of resveratrol on the intestinal mucosal barrier in rats with severe acute pancreatitis. Med Sci Monit, 2009; 14: BR14-9.

6. Gencay C, Kilicoglu SS, Kismet K, et al. Effect of honey on bacterial translocation and intestinal morphology in obstructive jaundice. World J Gastroenterol. 2008; 14: 3410-5.

7. Natividad JM, Verdu EF. Modulation of intestinal barrier by intestinal microbiota: Pathological and therapeutic implications. Pharmacol Res. 2013; 69:42-51.

8. Van Felius ID, Akkermans LM, Bosscha K, et al. Interdigestive small bowel motility and duodenal bacterial overgrowth in experimental acute pancreatitis. Neurogastroenterol Motil. 2003; 15: 267-76.

9. Akdas S, Turan B, Durak A, et al. The Relationship Between Metabolic Syndrome Development and Tissue Trace Elements Status and Inflammatory Markers. Biol Trace Elem Res. 2020; 198:16-24.

10. Soussi A, Gargouri M, El Feki A. Effects of co-exposure to lead and zinc on redox status, kidney variables, and histopathology in adult albino rats. Toxicol Ind Health. 2018; 34: 469-80.

11. Maremanda KP, Khan S, Jena G. Zinc protects cyclophosphamide-induced testicular damage in rat: Involvement of metallothionein, tesmin and Nrf2. Biochem Biophys Res Commun. 2014; 445:591-6.

12. Tang QQ, Su SY, Fang MY. Zinc Supplement Modulates Oxidative Stress and Antioxidant Values in Rats with Severe Acute Pancreatitis. Biol Trace Elem Res. 2014; 159: 320-4.

13. Tang QQ, Zhang JL, Wang XY, et al. Regulatory effect of octreotide on levels of zinc, copper, chromium, manganese and serum amylase in rats with severe acute pancreatitis. Trace elem electroly. 2013; 30:14-7.

14. Spormann H, Sokolowski A, Letko G. Effect of temporary ischemia upon development and histological patterns of acute pancreatitis in the rat. Pathol Res Pract. 1989; 184: 507-13.

15. Woodcock NP, Sudheer V, El-Barghouti N, et al. Bacterial translocation in patients undergoing abdominal aortic aneurysm repair. Br J Surg. 2000; 87:439-42.

16. Chin KF, Kallam R, O'Boyle C, et al. Bacterial translocation may influence long-term survival in colorectal cancer patients. Dis Colon Rectum. 2006; 50: 323-30.

17. MacFie J, Reddy BS, Gatt M, et al. Bacterial translocation studied in 927 patients over 13 years. Br J Surg. 2006; 93: 87-93.

18. Reddy BS, MacFie J, Gatt M, et al. Commensal bacteria do translocate across the intestinal barrier in surgical patients. Clin Nutr. 2007; 26: 208-15.

19. MacFie J. Current status of bacterial translocation as a cause of surgical sepsis. Br Med Bull. 2004; 71:1-11.

20. Deitch EA. Gut-origin sepsis: evolution of a concept. Surgeon. 2012; 10:350-6.

21. Li Q, Wang C, Tang C, et al. Bacteremia in the patients with acute pancreatitis as revealed by $16 \mathrm{~S}$ rRNA gene-based techniques. Crit Care Med. 2013; 41:1938-50

22. Morrison CP, Teague BD, Court FG, et al. Experimental studies of serum cytokine concentration following pancreatic electrolytic ablation. Med Sci Monit. 2003; 9:BR43-6.

23. Wan YD, Zhu RX, Bian ZZ. Improvement of Gut Microbiota by Inhibition of P38 Mitogen-Activated Protein Kinase (MAPK) Signaling Pathway in Rats with Severe Acute Pancreatitis. Med Sci Monit. 2019; 25: 4609-16.

24. Noor MT, Radhakrishna Y, Kochhar R, et al. Bacteriology of infection in severe acute pancreatitis. JOP. 2011; 12:19-25.

25. Wu ZW, Ling ZX, Lu HF, et al. Changes of gut bacteria and immune parameters in liver transplant recipients. Hepatobiliary Pancreat Dis Int. 2012; 11:40-50.
26. Tan C, Ling Z, Huang $Y$, et al. Dysbiosis of intestinal microbiota associated with in ammation involved in the progression of acute pancreatitis. Pancreas. 2015; 44: 868-75.

27. Prasad AS. Effects of zinc deficiency on Th1 and Th2 cytokine shifts. J Infect Dis. 2000; 182:S62-8.

28. Zhong W, Li Q, Sun $\mathrm{Q}$, et al. Preventing gut Leakiness and endotoxemia contributes to the protective effect of zinc on alcohol induced steatohepatitis in rats. J Nutr. 2015; 145: 2690-8.

29. Zhong W, McClain CJ, Cave M, et al. The role of zinc deficiency in alcohol-induced intestinal barrier dysfunction. Am J Physiol Gastrointest Liver Physiol. 2010; 298: G625-33.

30. Wessels I, Cousins RJ. Zinc dyshomeostasis during polymicrobial sepsis in mice involves zinc transporter Zip14 and can be overcome by zinc supplementation. Am J Physiol Gastrointest Liver Physiol. 2015; 309: G768-78.

31. Knoell DL, Julian MW, Bao S, et al. Zinc deficiency increases organ damage and mortality in a murine model of polymicrobial sepsis. Crit Care Med. 2009; 37:1380-8.

32. Reed S, Neuman H, Moscovich S, et al. Chronic zinc deficiency alters chick gut microbiota composition and function. Nutrients. 2015; 7:9768-84.

33. Mahmood A, Tanweer Khaliq, Sajjad-ur-Rahman, et al. Immunomodulation and strenghthening of serum mineral profile by dietary supplementation of protein, probiotics and vitamins (C and $\mathrm{E})$ in molted layer breeders. Pak J Agri Sci. 2016; 53: 265-70.

34. Vujasinovic M, Hedström A, Maisonneuve P, et al. Zinc deficiency in patients with chronic pancreatitis. World J Gastroenterol. 2019; 25: 600-7.

35. Milnerowicz H , Jablonowska M , Bizoń Anna. Change of Zinc, Copper, and Metallothionein Concentrations and the Copper-Zinc Superoxide Dismutase Activity in Patients With Pancreatitis. Pancreas. 2009; 38: 681-8.

36. Osman Güler, Akturan S, Kisli E, et al. Acute pancreatitis, bacterial translocation, and different octreotide regimens: An experimental study. Surgery today. 2009; 39: 876-83.

37. Russo AJ. Analysis of Plasma Zinc and Copper Concentration, and Perceived Symptoms, in Individuals with Depression, Post Zinc and Anti-Oxidant Therapy. Nutrition and Metabolic Insights. 2011; 4:19-27.

38. Powell S. The antioxidant properties of Zn. J Nutr. 2000; 130: 1447S-54.

39. Bao S, Liu MJ, Lee B, et al. Zinc modulates the innate immune response in vivo to polymicrobial sepsis through regula- tion of NF-kappaB. Am J Physiol Lung Cell Mole Physiol. 2010; 298: L744-54.

40. Bolick DT, Kolling GL, Ii JHM, et al. Zinc deficiency alters host response and pathogen virulence in a mouse model of enteroaggregative escherichia coli-induced diarrhea. Gut Microbes. 2014; 5:618-27.

41. Queiroz CAD, Fonseca SGC, Priscila B, et al. Zinc treatment ameliorates diarrhea and intestinal inflammation in undernourished rats. Bmc Gastroenterology. 2014; 14: 136.

42. Riveras E, Azocar L, Moyano TC, et al. Transcriptomic pro les reveal differences in zinc metabolism, inflammation, and tight junction proteins in duodenum from cholesterol gallstone subjects. Sci Rep. 2020; 10: 7448. 